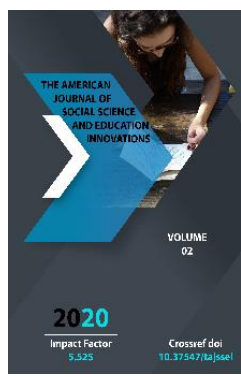

\title{
Innovative-Methodological And Organizational-Pedagogical Prospects For Activating Social Activity Of The Future Teachers
}

Sobirova Dilorom Haydaralievna

Teacher, Gulistan State University, Uzbekistan

Copyright: Original content from this work may be used under the terms of the creative commons attributes 4.0 licence.

\section{ABSTRACT}

To develop students' 21st century skills and render education more responsive to the challenges of a knowledge-based society, teachers' development has been constantly called for. The conception of teaching as a life-long learning process is gaining momentum with the variety of conferences, courses/programmes, and published materials supporting it. But, to develop as teachers we need to understand the nature of this development. Does it mean professional, personal or social development? This article aims to clarify the meaning of teacher development through explaining what teacher professional, personal and social development mean and how these relate to teacher development.

\section{KEYWORDS}

Educational information resource; listening; vocational guidance; authentic material; ICT.

\section{INTRODUCTION}

The work of the teacher is very specific. Pedagogical is a special type of activity of adult citizens that is useful for society, consciously aimed at preparing children for life in accordance with existing political, economic, aesthetic, moral and other goals. As part of this work, an objective process of education is organized. The functions of social and educational activities are focused on improving and accelerating the preparation of the younger generation for life. This is due to the fact that teachers, realizing their tasks, use 
theoretical knowledge and practical experience within the system of special institutions. Many authors consider the separation of each function of professional pedagogical activity in isolation from others, while maintaining their interconnection. In the general system of teaching, three components were formed: communicative, organizational and constructive. For the implementation of each function of pedagogical activity, pedagogical skills, abilities and aspirations play a key role.

The educational process is implemented with the direct subordination of the tasks and goals set by the teacher. Key functions of pedagogical activity are:

1. Diagnostic. It is connected with the study of children, the determination of the level of psychological development of each child individually and the whole team as a whole.

2. Orientational prognostic. It is expressed in the ability to define the tasks, directions and goals of the educational process, as well as to plan its results.

3. Structural design. It involves the adequate formation of educational work.

4. Organizing. This function of the teacher's pedagogical activity is characterized by the active involvement of children in the educational process. It involves the emotional and moral stimulation of each child.

5. Explanatory. It involves informing in various fields of knowledge with the latest scientific advances.

6. Communicative stimulating. This function is based on the formation of an atmosphere of cooperation, the humane attitude of the teacher towards children.

7. Analytical and estimated. It consists in the analysis of the process of training and education, the ability to make appropriate adjustments in it.

8. Research and creative. This function involves the understanding and development of theoretical positions, the use in their work the results of their own analysis and the achievements of their colleagues.

Professional development, also referred to professional learning by teacher already engaged in professional practice, is the process of developing the necessary knowledge-base and skills teachers require to carry out their role effectively. This does not only involve learning new theoretical teaching ideas and suggestions, but also trying them out and learning how to make them more effective within their teaching contexts.

Teachers' ongoing reflection, evaluation and analysis of their own practices are necessary elements of their professional development as these can support them construct new teaching theories and improve more their performances (learning-by-doing approach as put forward by Whitford, 1994). Indeed, being critical, reflective on teaching experiences and motivated to bring change and improvement are essential for teachers' professional development.

Becoming professionals, or as DarlingHammond and Bransford (2005) explain entails being 'adaptive experts' which is the intent of teachers' engagement in such a process. Today's teachers should be experts in their work, i.e., planning their lessons, 
communicating, managing, carrying out and assessing the activities of the teaching learning process more effectively, and meanwhile adaptive, i.e., being flexible to different students' needs and preferences.

Professional development and training are not synonymous. Let's first explain what teacher training means. Teacher training aims to help teachers learn the necessary pedagogical knowledge and skills. More particularly, it is mostly concerned with the "How". For instance, how to use a particular digital tool and integrate it into a given lesson, how to teach mixed ability classes, how to flip the classroom, etc.

Professional development incorporates training, but it emphasizes more teachers' awareness of their teaching contexts and how to apply such practical skills in these contexts. This is because teaching is a challenging job that requires more teacher flexibility and creativity to deal successfully with the unexpected and cater for the different students' needs in each classroom. Thus, professional development's aim is to aid teachers learn how to adjust their teaching to their students' learning needs through understanding the "Why" or rational behind any pedagogical decision made or choice in relation to their teaching contexts.

An effective professional development should, therefore, encourage teachers to experiment with new ideas or tools in their teaching contexts, reflect on how these impact their students' learning, make further decisions to achieve their intended objectives and share their experiences. Its elements should include: reflective discussion sessions based on previous and current classroom experience, collaborative learning, reflective diaries/journals or portfolios, and teacher-led activities that provide multiple opportunities for teachers' choice, autonomy and active learning.

There are schools, colleges and universities that provide in-service educational opportunities for teachers through planned programs that intend to address their needs (formal professional development). But, professional development can also be selfinitiated (informal). There are plenty of resources teachers can turn to if they want to develop professionally. These can include, for instance, self-monitoring through selfobservation (video recording), reading books, journals' articles in relation to teaching, taking online courses, attending professional development conferences, conducting action research, etc.

Personal development or self-development refers to possessing personal strengths and characteristics that aid teachers define and make sense of their teaching practice and of themselves as individuals. This is through developing the necessary life skills that can help them grow in and outside their profession.

There are a range of life skills that assist teachers in coping with the challenges of everyday living. Getting organized, solving problems, engaging and caring about students are among the key life skills that teachers need in the profession.

Because teachers' professional role can be affected by their personal-life factors, they need to develop certain life skills related to their personal life. These can include balancing their professional and personal lives, coping with family pressure, stress and negative 
emotions (like anger, sadness, etc.), making effective decisions concerning their health, etc.

Personal development is a powerful tool to reach a well-defined and healthy sense of self as teachers (self-concept enhancement), which can result in positive self-esteem and self-confidence. Besides, it enables teachers to recognize, understand and manage their emotions thereby having good intrapersonal skills (emotional intelligence).

This capacity has been labeled 'social competence'. According to Huitt and Dawson (2011), social competence includes: (1) being aware of one's own and others' emotions, (2) managing impulses and behaving appropriately, (3) communicating effectively, (4) forming healthy and meaningful relationships, (5) working well with others, and (6) resolving conflict.

Thus, the process of developing such capacity involves the affective (emotions), cognitive (decision-making), and social domains (communication). Teaching is based on interpersonal relationships. So, communicating effectively with students, colleagues, other staff members, and parents and maintaining healthy professional relationships are skills teachers need for a successful career and well-being.

Teacher development occurs when these aspects of development are occurring: personal, professional and social development. This is because teacher development is a learning process, so emotions have a say on how the brain functions; positive emotions (like motivation) boost engagement in learning. Quality knowledge and understanding are of utmost importance to learning (cognition). Besides, the social nature of learning is crucial since this process is actively constructed through social interaction and negotiation with others

These building blocks of teacher development are interrelated, i.e., each development's aspect depends on the other aspects. To illustrate, a teacher who cannot manage his emotions (not personally developed) is not likely to control or manage effectively his classroom and thus interact effectively with his students (cannot develop professionally and socially). When feeling angry he will burn out, lose control, treat students badly and he may even forget the lesson plan. These types of development should be the intended outcome of any teacher development intention or programme.

Teacher development is an evolving learning process. This learning process is ongoing and endless. Even if a teacher has achieved certain development, he still needs to learn along his whole life and career. In this rapidly changing world, preparing skilled workers and engaged citizens is becoming a game changer.

Therefore, teacher development must be every teacher's passion, concern and intended aim. Such development does not only depend on formal learning, but it can also be selfinitiated by teachers. In this case, finding the right professional development activities that fit once own needs and preferences remains a necessary decision to make. Whether it is formal or informal, updating, innovating and searching are the three pillars of teacher development (Cárdenas et al., 2010). Interest and commitment to change are also vital for this process.

The implementation of pedagogical functions requires not only certain knowledge from a specialist. The effectiveness of achieving the goals depends on many factors. Among them 
are personal qualities, and the level of competence, and the ability to selfdevelopment, self-education. The activity of a teacher is very laborious, requires a lot of time and mental costs. The implementation of the functions of pedagogical activity should be carried out according to a clear plan, drawn up on the basis of the results of diagnostics, taking into account the peculiarities of the children's team and using the experience of advanced modern teachers.

\section{REFERENCES}

1. Cárdenas, M. L., González, A., \& Álvarez, J. A. (2010). In service English teachers' professional development: Some conceptual considerations for Colombia. Folios, 31, 49-68.

2. Darling-Hammond, L., \& Bransford, J. (2005). Preparing teachers for a changing world: What teachers should learn and be able to do? San Francisco: John Wiley \& Sons.

3. Huitt, W. \& Dawson, C. (2011, April). Social development: Why it is important and how to impact it. Educational Psychology Interactive. Valdosta, GA: Valdosta State University. Retrieved from http://www.edpsycinteractive.org/pap ers/socdev.pdf

4. Whitford, B. L. (1994). Permission, persistence, and resistance: Linking high school restructuring with teacher education reform. In L. DarlingHammond (Ed.), Professional development schools: Schools for developing a profession (pp. 74-97). New York: Teachers College Press. 